Article

\title{
Investigating Forest Disturbance Using Landsat Data in the Nagagamisis Central Plateau, Ontario, Canada
}

\section{K. Wayne Forsythe ${ }^{1, *}$ and Grant McCartney ${ }^{2}$}

1 Department of Geography, Ryerson University, 350 Victoria Street, Toronto, ON M5B2K3, Canada

2 Tembec Inc., 1 Government Road, Kapuskasing, ON P5N 2Y2, Canada;

E-Mail: Grant.McCartney@ tembec.com

* Author to whom correspondence should be addressed; E-Mail: forsythe @ geography.ryerson.ca; Tel.: +1-416-979-5000 (ext. 7141); Fax: +1-416-979-5362.

Received: 20 December 2013; in revised form: 10 February 2014 / Accepted: 17 February 2014 / Published: 4 March 2014

\begin{abstract}
The Nagagamisis Central Plateau (located in Northern Ontario, Canada) is an area of distinct natural and cultural significance. The importance of this land was officially recognized in 1957 through the establishment of the Nagagamisis Provincial Park Reserve. The park has experienced significant expansion since its inception and is currently under development as one of Ontario Parks 'Signature Sites'. Since the 1980s, timber harvest activity has led to widespread forest disturbance just outside of the park boundaries. This research is focused on the detection of stand level forest disturbances associated with timber harvest occurring near Nagagamisis Provincial Park. The image time-series data selected for this project were Landsat TM and ETM+; spanning a twenty-five year period from 1984 to 2009. The Tasselled Cap Transformation and Normalized Difference Moisture Index were derived for use in unsupervised image classification to determine the land cover for each image in the time-series. Image band differencing and raster arithmetic were performed to create maps illustrating the size and spatial distribution of stand level forest disturbances between image dates. A total area of $1649 \mathrm{~km}^{2}$ or $26.1 \%$ of the study area experienced stand level disturbance during the analysis period.
\end{abstract}

Keywords: forest disturbance; change mapping; time-series; Nagagamisis Provincial Park; Landsat; land cover 


\section{Introduction}

The boreal forest occupies a total area of three million square kilometers within Canada [1]. It is a dynamic ecosystem that changes continually as a function of natural (succession, fire and insects) and anthropogenic disturbance events (land use change and timber harvest) that can have significant ecological effects $[2,3]$.

Cyclical forest fires are a primary cause of stand level disturbance in the Canadian boreal ecosystem [2,4-6]. Anthropogenic resource extraction activities such as timber harvest have also had a large physical impact on the boreal ecosystem in recent history [7,8]. The size, frequency and intensity of fire regimes and timber harvest vary widely in terms of tree mortality totals and vegetation/biomass loss within a disturbed area [8]. Both fire and timber harvest disturbances impart significant and unique ecological effects on the forest landscape [2].

Across Canada, roughly one quarter of the boreal ecosystem is managed by commercial timber harvest operations under public land lease agreements. In Ontario, a total area of $300,000 \mathrm{~km}^{2}$ of boreal forest is managed and harvested under Sustainable Forest License (SFL) agreements [8]. These agreements between the Ontario provincial government and private timber harvest companies involve a formal proposal of harvest strategies and silviculture activity within geographic areas known as forest management units (FMU) [9]. These areas are subject to regular audits to ensure the contractors are fulfilling these agreements. Over the period of 1975 to 1993 , there was a $125 \%$ increase in the amount of boreal forest harvested annually in Canada [2]. Between 1951 and 1960, the total clearcut area in Ontario was $5,000 \mathrm{~km}^{2}$ and increased to more than $20,000 \mathrm{~km}^{2}$ between 1981 and 1990 [10].

In Ontario, there is a long history of preservation and protection efforts for areas of significant natural and cultural heritage dating back to 1893 with the establishment of Algonquin Provincial Park. Following this, the passing of the Provincial Parks Act in 1913 led to the establishment of more than 150 Provincial Parks by 1983 [11]. These protected areas contribute to maintaining a healthy ecosystem, protecting wildlife habitat and enhancing scientific understanding of forest ecosystems [11]. Since the Provincial Parks Act, many land use planning initiatives have been undertaken across the province to strengthen Ontario's protected area network of parks, conservation reserves and wilderness areas. These initiatives have been integrated into provincial policy through implementation of the Lands for Life (LFL) (1997) and the Ontario Living Legacy (OLL) (1999) land use planning strategies. The purpose of these strategies is to guide the management and planning of land use on crown land including the expansion of the protected area network [12]. In 2005, the protected area network consisted of a total area of more than $80,000 \mathrm{~km}^{2}$ in Ontario [13]. Under the Ontario Living Legacy strategy, nine flagship areas referred to as "signature sites" are to be developed as showcases of Ontario's natural and cultural heritage [11]. One such signature area is the Nagagamisis Central Plateau, which is located within the study area chosen for this research.

The use of remotely sensed data has been identified as an accurate and cost effective method for monitoring land cover changes on the earth's surface [14-18]. Remote sensing provides an effective method for monitoring forest change in vast remote areas and can contribute insight to policy and management objectives [18-20]. Periodic forest cover disturbance monitoring is necessary for the assessment of sustainable forest management strategies and is useful for monitoring environmentally significant areas [18,21,22]. 
The Landsat program, run by the United States Geological Survey (USGS), is the longest running source of remote sensing data used for earth observation, and the data are freely available [14]. The $30 \mathrm{~m}$ spatial resolution of the Landsat Thematic Mapper (TM) and Enhanced Thematic Mapper Plus (ETM+) sensors provides adequate resolution to resolve both natural and anthropogenic stand level disturbances that occur within forest ecosystems [2,18].

The TM and ETM+ sensors provide a wide spectral resolution, which extends through the visible, near infrared, and short wave infrared portions of the electromagnetic spectrum. Landsat also provides a moderate temporal resolution with a revisit period of 16 days for most locations on Earth [14]. In the literature, Landsat data have been used for many forest classification and change detection applications such as: forest fragmentation, insect infestation, fire regime monitoring, timber volume estimation and forest succession/disturbance $[2,14,18,23,24]$.

This study is focused on the detection of disturbances associated with timber harvest activity that results in a near complete removal of all trees within an area. This removal of vegetation biomass is referred to in the literature as a stand level disturbance [18,24,25]. In this research, stand level disturbances can be described as areas of approximately 900 square meters (the size of an individual pixel) that can be detected and mapped using Landsat imagery [24]. This also includes the possibility that some mixed pixels on the boundaries of disturbed zones will be detected. The amount of forest land cover, size, and severity of disturbances has been used as an indicator of environmental condition such as habitat fragmentation and carbon flux within Canada [15,26]. Landsat imagery has been shown to be an effective dataset for the detection of stand level disturbance as a result of timber harvest activity [2,19,24,27]. Repeated land cover mapping and analysis of the same study site over a period of time allows for evaluation of changes in forest cover [18,22,28-31]. Many studies make use of multiple image dates in order to detect changes in land cover through time $[2,17,19]$. There are many different analytical methods presented in the literature yet, there is no consensus on the selection of methods that can be applied to all land cover applications with equal success and accuracy [15,32,33]. In the comprehensive review of Coppin and Bauer [34], many change detection techniques are tested and the authors conclude that image differencing and linear transformations perform better than other change detection methods [35].

The overall objective of this research is to investigate the spatial patterns of stand level forest disturbance and expansion in the vicinity of a provincial protected area over time. This research uses a medium resolution image time-series; spanning a twenty-five year period from 1984 to 2009. The detection of forest disturbance events on the land surface was examined on an interval ranging from two to five years. Image band differencing and raster arithmetic were utilized to create disturbance maps that illustrate the size, spatial distribution and rate of stand level forest disturbances within the study site. This analysis also made use of the Tasselled Cap Transformation (TCT) [18] and the Normalized Difference Moisture Index (NDMI) [18,36] to extract additional spectral information from the original Landsat image bands. Finally, unsupervised classification was used to determine the land cover for each image scene. 


\section{Study Area}

The study area covers an area of $6303 \mathrm{~km}^{2}$ located in the Ontario Shield boreal eco zone and Lake Abitibi eco region (Figure 1). The climate of the boreal region of Ontario is characterized by long cold winters, and cool to moderately warm summer seasons [37]. The site is characterized by moderate topography with elevations ranging from 89 to $488 \mathrm{~m}$ above mean sea level. The land cover is dominated primarily by large tracts of mixed deciduous and boreal forest consisting of coniferous trees (black spruce, white spruce, jack pine, balsam, European larch) and deciduous tree species (poplar, trembling aspen and white birch). This forested landscape is dotted with hundreds of lakes, peatlands and wetlands. The fluvial features within the site are a part of the Kenogami watershed, which drains north towards the Hudson Bay lowlands.

Figure 1. Study area location in the province of Ontario, Canada.

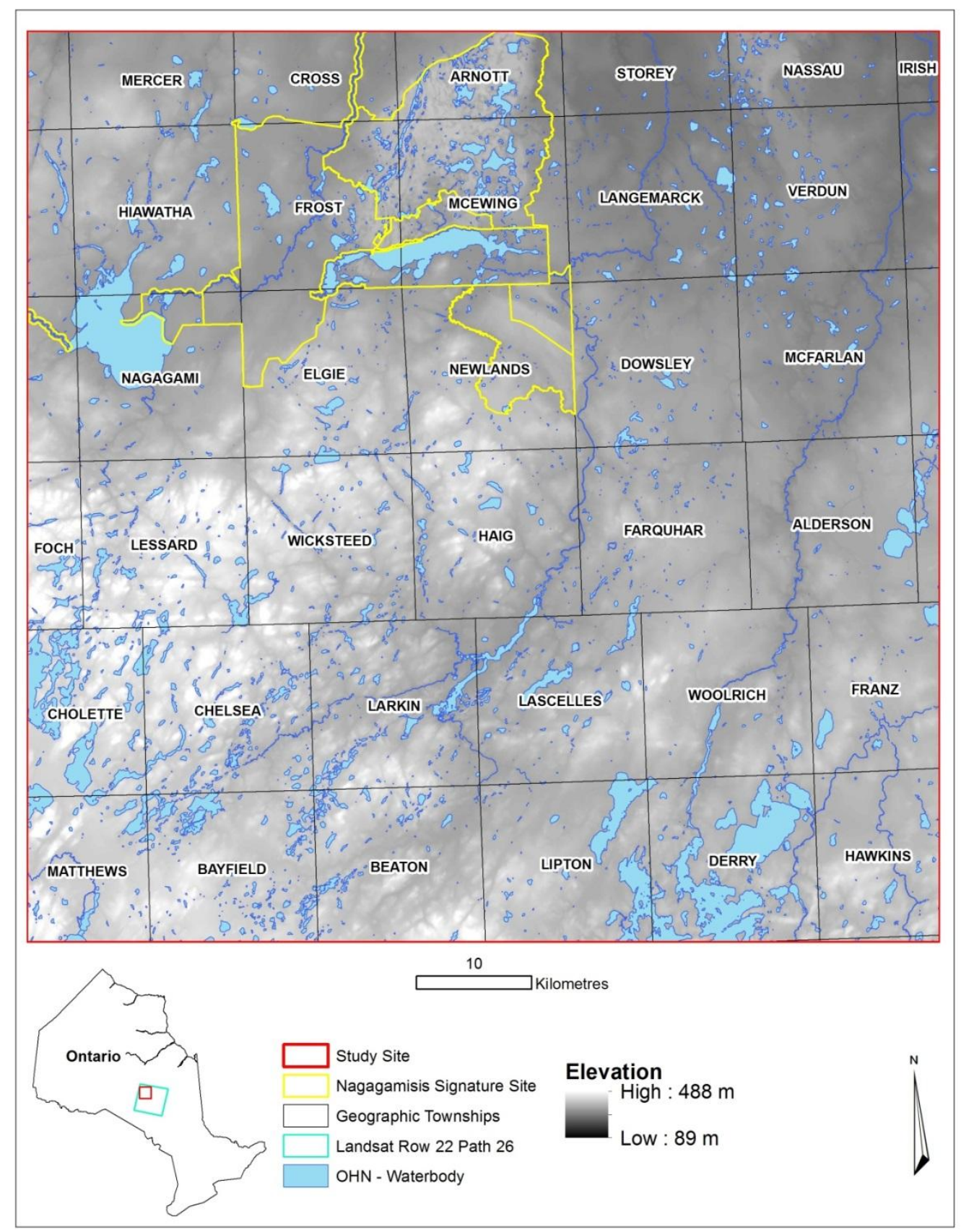


Figure 2. Nagagamisis central plateau signature site.

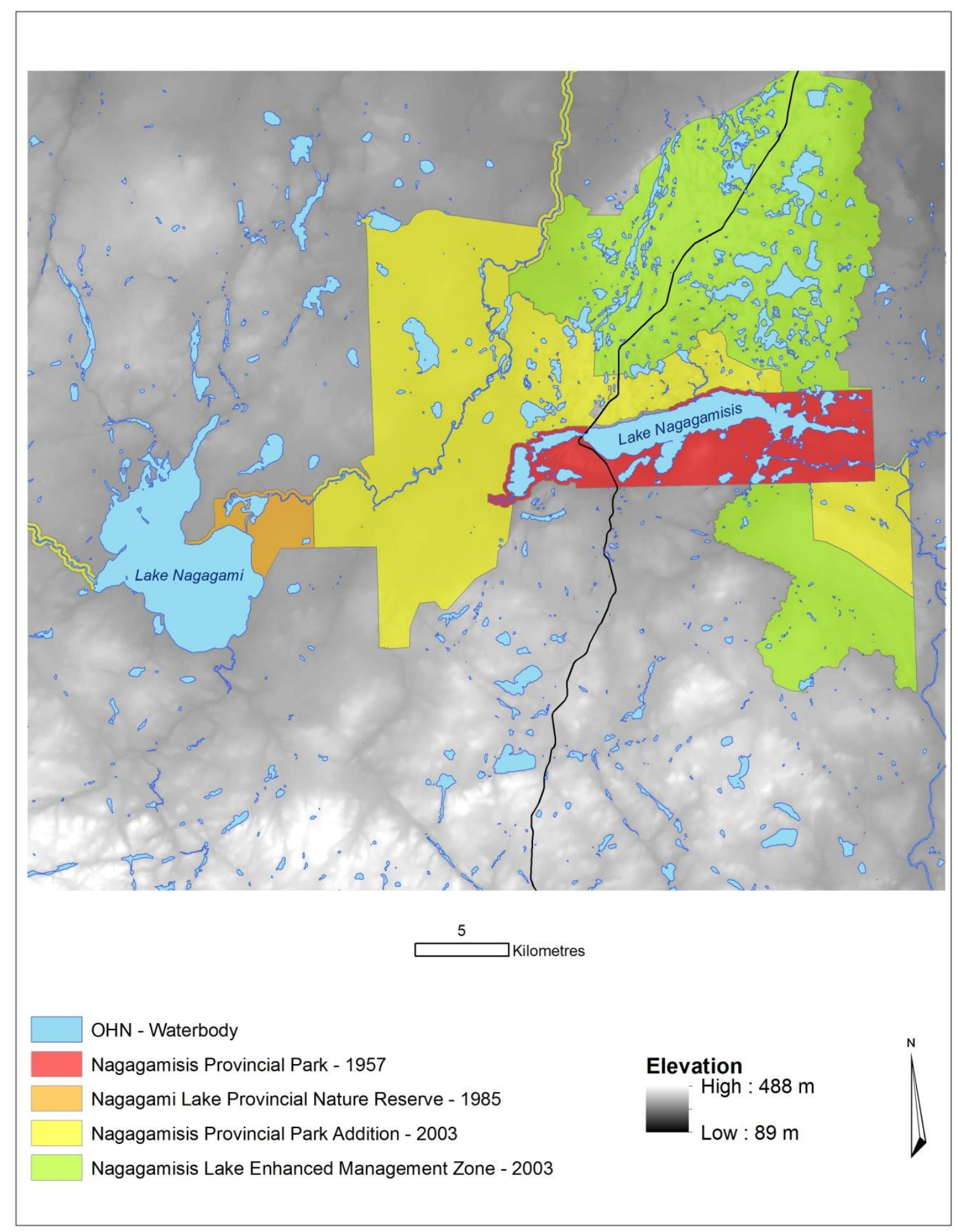

The communities in this part of Ontario are small, isolated population centers that rely heavily on the forest industry [38]. Hearst, Ontario is about twenty times more dependent on the forest industry than the provincial average. There are no other primary industries in this area that employ such a significant number of people [38]. The dominant land use within the study site is large forest management units (FMU) zoned for commercial timber harvest. Portions of four FMUs are represented within the study area. Roughly half of the study site is located within the Nagagami FMU 
$\left(3020 \mathrm{~km}^{2}\right)$ and the other half in the Hearst forest $\left(2942 \mathrm{~km}^{2}\right)$ while smaller portions are located in the White River $\left(193 \mathrm{~km}^{2}\right)$ and Big Pic $\left(155 \mathrm{~km}^{2}\right)$ forest management units. There are several protected areas of natural and cultural significance located within the study site such as nature reserves and Provincial Parks protected as the Nagagamisis Central Plateau signature site that are of particular interest to this research.

The Nagagamisis Central Plateau is an area of distinct natural and cultural significance in the boreal shield ecosystem. It is located $30 \mathrm{~km}$ north of Hornepayne and $130 \mathrm{~km}$ southwest of Hearst, Ontario (Figure 2). The park's Cree aboriginal name Nagagamisis, means "lake with fine, sandy shores" [39]. There are two large water bodies in the park, Lake Nagagami is located in the western portion of the park and Lake Nagagamisis to the east is a slender water body that has its long axis in the east-west direction. This area is home to unique glacial features including the Arnott Moraine and rare kettle, esker and kame features [12]. It also has a human history and cultural heritage dating back thousands of years [12]. The importance of this land was officially recognized in 1957 through the establishment of the Nagagamisis Provincial Park Reserve.

Since its inception, the park has experienced significant expansion and is currently under development as one of Ontario Parks "Signature Sites". The present park consists of four distinct components. The original Nagagamisis Provincial Park Reserve was established in 1957 and the Nagagami Lake Provincial Park was established in 1985 under the Ontario Provincial Parks Act. In 2003 (under the OLL), a park expansion of 32,680 ha resulted in the joining of the two parks to encompass Lake Nagagami, Lake Nagagamisis, the Foch-Nagagami River, surrounding topographic features and forest stands [39]. The addition and creation of an enhanced management zone (EMZ) expanded the park to the north and south and includes lands in thirteen geographic townships.

The EMZ included areas that have previously been subject to clearcut timber harvesting. This activity has been a prevalent agent of disturbance in the forestlands surrounding Nagagamisis Provincial Park. The challenge remains to protect areas of natural and cultural significance while maintaining the economic stability of the surrounding communities that are dependent on forestry and the sustainable utilization of forest resources [38].

\section{Data and Methodology}

The United States Geological Survey (USGS) Earth Explorer Landsat data archive (http://earthexplorer.usgs.gov/) was the source of the image data utilized in this study. Landsat 5 TM and Landsat 7 ETM+ level 1 systematic and terrain corrected (L1T/G) image data were acquired for the study site which was contained within Path 22, Row 26 World Reference System-2 (WRS-2). The Landsat visible and infrared image bands 1-5 and 7 for both the TM and ETM+ sensors have compatible spatial resolutions of $30 \mathrm{~m}$ and nearly identical spectral resolution.

Over thirty, (May-September) images for the study period of 1984 to 2009 were acquired with a goal of capturing near anniversary growing season conditions at the nearest possible inter annual temporal interval. This required visual inspection of atmospheric conditions in each image scene for the distribution and size of cloud cover or haze. Only images that were cloud free over the study site were selected for use in the analysis. The final image list is presented in Table 1. 
Table 1. Landsat image characteristics.

\begin{tabular}{cccc}
\hline Acquisition Date & Satellite and Sensor & Cloud Cover & Scene Identifier \\
\hline 12/08/1984 & Landsat 5 TM & less than 10\% & LT50220261984225PAC00 \\
18/08/1986 & Landsat 5 TM & less than 10\% & LT50220261986230XXX03 \\
01/09/1991 & Landsat 5 TM & less than 10\% & LT50220261991244PAC03 \\
08/06/1995 & Landsat 5 TM & less than 10\% & LT50220261995159PAC01 \\
15/07/2000 & Landsat 7 ETM+ & less than 10\% & LE70220262000197EDC00 \\
22/08/2002 & Landsat 7 ETM+ & less than 10\% & LE70220262002234EDC00 \\
08/05/2007 & Landsat 5 TM & less than 10\% & LT50220262007128GNC01 \\
$02 / 09 / 2009$ & Landsat 5 TM & less than 10\% & LT50220262009245GNC01 \\
\hline
\end{tabular}

Frequent cloud cover was a limiting factor in the image acquisition process. This resulted in the use of images that span a five-month range and contain almost the entire phenological and foliage cycle of the deciduous trees in the study site. Kennedy et al. [25] state that consistency of seasonality trumps absence of clouds as the highest priority in disturbance mapping, but other images were not available for this study. Dynamic atmospheric conditions also restricted the study site to only a portion of the original 185 by $185 \mathrm{~km}$ image tile. This resulted in a variable inter-annual interval with two, four and five year time steps and not annual, anniversary image intervals.

The Thematic Mapper Tasselled Cap Transformation (TCT) [40] reduces the six original Landsat reflectance bands 1-5 and 7 to three components representative of physical land surface characteristics known as brightness (TCT1), greenness (TCT2) and wetness (TCT3) [18,41]. These three components account for most of the variance in an image scene and provide a reduction in data volume with minimal information loss [36]. The TCT has been demonstrated in the literature as effective for vegetation mapping and temporal land cover change detection [14,18,42]. In recent research, the TCT performed significantly better than the original Landsat bands for detecting change in a forested landscape [43]. Forested lands that have recently been disturbed will exhibit a higher brightness, lower greenness and wetness values than undisturbed mature forest stands [43]. Of particular interest is the wetness component for its sensitivity to plant and soil moisture, canopy structure and shadow [35,40,44,45].

The Normalized Difference Moisture Index (NDMI) is derived using Landsat bands four (NIR) and band five (SWIR) [46]. The equation is: NDMI $=($ Band $4-$ Band 5)/(Band $4+$ Band 5). The NDMI algorithm is very similar to the Normalized Difference Vegetation Index (NDVI) that is commonly used in forest classification and to estimate characteristics such as leaf area, biomass, and canopy closure [47]. In a direct comparison, NDMI has been shown to be a more accurate measure than the widely used NDVI for detection of forest harvest activity [35].

A visual investigation was carried out to ensure that all of the selected images were properly co-registered and correctly aligned prior to analysis. The full Landsat scenes were subset to isolate the specific study area that included the Nagagamisis Central Plateau Signature Site and surrounding commercial forest management units. The resulting subset image is 2646 pixels by 2647 lines covering an area of $6303 \mathrm{~km}^{2}$.

Although radiometric correction of image time series datasets is recognized as an option for remote sensing projects [48] to account for variation in atmospheric and sun sensor geometry, no additional corrections were completed on the Level 1 data products used for this study. Radiometric differences 
do exist between the analysis images, but the noise associated with temporal differences is minimal relative to the strong signal of stand level disturbance events [24,27]. It was determined that the effort and time needed to atmospherically correct the imagery would not significantly affect the accuracy of the results $[17,27]$.

Image band differencing involves the subtraction of pixels between two co-registered raster datasets to identify areas that have experienced change [20]. Landsat band five short wave infrared (SWIR) difference images were produced for each inter annual image pair. After experimenting with image band differencing using bands three, four and five, the band five (SWIR) differencing result was selected as the most appropriate for identifying areas of stand level forest disturbance. The SWIR channel is widely used in remote sensing for its sensitivity to vegetation structure, density, volume and leaf moisture content $[40,44]$. The short wave infrared bands five and seven have been shown to contain more information about conifer and hardwood forests than any other Landsat bands [44]. In the context of the boreal forest, band five has been effective for classification of clearcut harvest activity [48].

The results of the band differencing operations for each time step of the analysis were saved as unsigned 8-bit raster datasets. When displayed in greyscale, these datasets are representative of changes to the forest cover between two image dates. Areas of forest that were disturbed prior to the beginning of each image time step appear in dark (black) tones that represent lower change values. While areas that were disturbed during each time step are shown in light (white) tones that represent higher change values. Areas that experienced no change during the time step are shown in shades of grey. These band difference images reveal the extent and spatial distribution of stand level forest disturbance and regeneration during each temporal image pair. Similar to Masek et al. [16,18] and Forsythe and Waters [17], not all of the changes in the difference image are related to the feature that is the analysis target (in this case disturbance change). Unsupervised classification methods were used to cluster the output band differencing raster datasets into three information classes based on the pixel values contained within the difference images. This eliminated the need to use thresholds to identify groupings in the data. These classes were: regenerative change, disturbance change and no change.

Following a stand level disturbance, harvested areas experience a relatively quick regeneration of broadleaf pioneer species such as alder, poplar and other shrubs that appear as regenerative change in the difference images. The age of surrounding mature forest stands is 70 to 100 years [49]. This research covers a time period of only 25 years, therefore the surface area of the regenerative change class continues to increase over the duration of the study. These areas differ from mature forest stands in both age structure and species composition. The true nature and composition of areas experiencing regeneration cannot be measured without in situ validation data. Since the focus of this work is on forest disturbance and not regeneration, these change areas are not included in the analysis. Alternatively, image classification is used to identify areas that remain disturbed at the later date of each image pair. The band differencing images are used only to identify areas that experience stand level disturbance between image pairs, as this is the primary focus of the study.

In order to exclude areas of regenerative change, they were reclassified as areas of no change to focus on change events related to stand level disturbance within each image time step. The image classification results for each image pair were used to identify areas of past disturbance. The output result of these procedures was a binary raster consisting of classes of disturbance change and no change. 
The unsupervised Iterative Self-Organizing Data Analysis (ISODATA) classification method was utilized to classify each image in the time series. It is a multivariate classification method used to identify spectral groupings (clusters) among unknown image pixels and aggregate them into a specified number of classes [16,50]. This method was found by Hame et al. [51] to be appropriate for change detection when validation data sets of forest change are not available. The original Landsat bands were utilized as classification inputs with the addition of Tasselled Cap and NDMI layers. These were included as they have been shown to be effective in improving classification results related to disturbance mapping $[18,36]$. The ISODATA classification algorithm was run with the parameters of 255 output spectral clusters and 20 iterations. The maximum number of 255 output clusters was specified in order to allow the algorithm to cluster the image pixels into as many clusters as needed. The algorithm usually identified between thirty and thirty-five output clusters. Sometimes specifying a lower number of output clusters leads to inaccurate results and poor classifications. These output clusters were then aggregated into three information classes, identifying pixels as undisturbed/regenerated forest, disturbed forest or water. This aggregation was completed through visual comparison of the original Landsat images and secondary image sources to assign each spectral cluster to an information class. All disturbance events including fire, timber harvest and related bush roads were classified together with no discrimination between change types. Finally the image differencing classifications and ISODATA classifications were combined for each analysis year to distinguish disturbance events in each analysis time period. This identified areas where stand level disturbance had occurred in the time period between image dates and is similar to procedures used by Masek et al. [16,18] and Forsythe and Waters [17].

A post classification accuracy assessment was utilized to determine the quality of information derived from the data analysis and classification processes for each image [52]. The aggregate classification for each image date was evaluated to determine its accuracy. Due to data availability and time constraints, a reference image was visually interpreted and compared to the classification result. The reference image used for the accuracy assessment was the Landsat TM/ETM+ image for each image date viewed as a true color composite of bands 3,2, and 1. A stratified random sample of 300 reference points was generated for the reference image and interpreted for each class of the aggregate classifications [53,54]. The sample points were stratified proportionally to the number of pixels in each of the three classes. Based on the results of the accuracy assessment, error matrices and accuracy statistics were generated for each image classification according to established accuracy assessment procedures [53,54]. This technique is a reliable method for accuracy assessment when ground truth data are not available $[35,55]$

\section{Results and Discussion}

The image classification from 1986 (Figure 3) provides a representative land cover map for the seven image dates chosen for this analysis. The classes represented are water (blue), undisturbed/regenerated forest (green) and disturbed forest (red). The water class represents all areas within the study site that contain water at the time of acquisition. The undisturbed/regenerated forest class represents all forested lands including mature forest stands and cutovers more than five years old that have experienced regrowth. The overall health, tree species composition and age of old cutover 
stands cannot be validated due to a lack of in situ sampling but is classified as undisturbed/regenerated due to its spectral characteristics. Pioneer species are the first vegetation to colonize a cutover area after stand level disturbance. They are mainly deciduous plants with a high leaf area that cause the surface to appear as healthy vegetation exhibiting low brightness, high greenness and wetness values even though the age structure of the stand has been completely altered [15]. The disturbed forest class, shown in red represents the amount of forested land that has experienced recent disturbance prior to the image acquisition date. The disturbed forest class represents areas that were recently disturbed and exhibit a high brightness, low greenness and wetness TCT values. These areas had been disturbed in the recent past and experienced little to no vegetative regeneration. The classification accuracy statistics for all image dates are presented in Table 2.

The results obtained through unsupervised classification were acceptable in terms of overall accuracy but a high degree of confusion between the disturbed and undisturbed/regenerated forest classes was sometimes a factor and varied greatly between image dates. This led to some classification results exhibiting low producer's accuracy values for the disturbed forest class. These low values could be the result of spectral similarity between undisturbed forest and areas that experienced partial harvest that did not remove all standing timber or harvested areas where significant regeneration occurred. There also seemed to be lower producer's accuracy in the early (May-June) and late (September) growing season images. This could be related to seasonal vegetation differences and leaf-on/leaf-off changes rather than disturbance. Furthermore, there is a possibility that increased complexity caused by harvest and regeneration within forest stands could have led to lower overall accuracy in the later image dates.

The classification results were not used in post classification "delta" change detection; instead the band five difference images were used to determine areas of disturbance. Delta change detection involves the classification of two images followed by pixel based comparison between the two classification results [56]. This technique was not utilized because it is subject to the compounding of classification errors, which may lead to inaccurate results [56]. Image differencing has been identified by Coppin and Bauer [34] to outperform other change detection techniques. Performing change detection using the band differencing technique avoided compounding classification errors in the change detection process and subsequent statistical analysis. The present disturbance class shown in the change maps is a result of band differencing. The undisturbed/regenerated forest and past disturbance classes of the disturbance maps are a product of image classification and are thus affected by the accuracy of the classification results.

Change detection mapping of disturbance events involved the arithmetic addition of the land cover classification results (as illustrated in Figure 3) and Landsat Band 5 difference images that were generated for each temporal period. The 1984-1986 disturbance map example (Figure 4) illustrates the four land cover types for each temporal period examined in this research. In the map: blue areas represent water, green areas represent undisturbed/regenerated forest, beige areas represent past disturbance experienced prior to the time step of each map and red areas represent present disturbance that occurred during the time period that was examined 
Figure 3. 1986 land classification results.

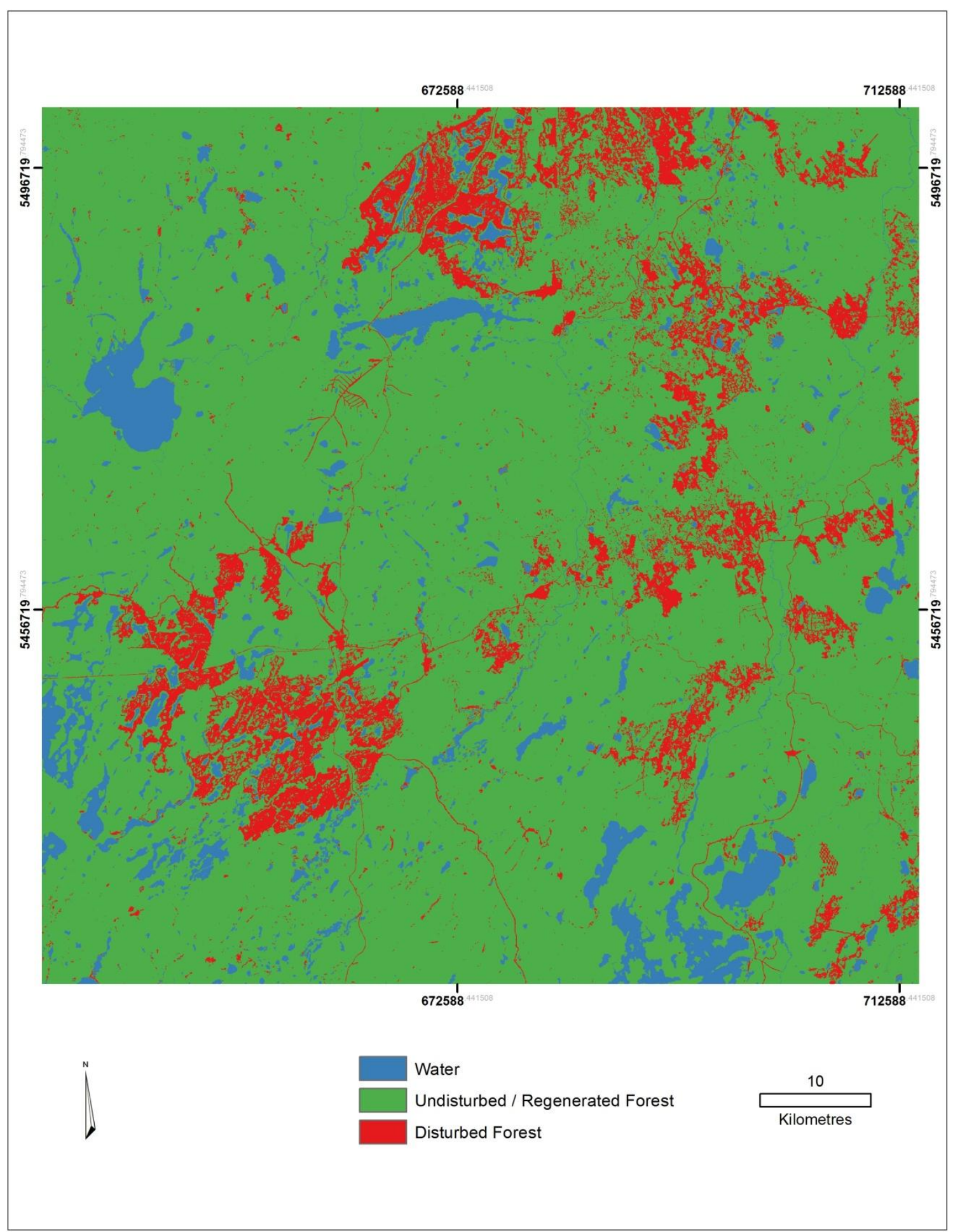

In the two year period from 1984-1986 (Figure 4), the present disturbance class contains $113 \mathrm{~km}^{2}$ ( $1.8 \%$ of the study site) of stand level disturbance. The map also shows an area of $577 \mathrm{~km}^{2}(9.1 \%$ of the study area) in the past disturbance class occurring prior to the beginning of this time step in 1984. The combined total surface area of disturbed forest in 1986 is $689 \mathrm{~km}^{2}$ or $11 \%$ of the study area. The average annual disturbance for the 1984-1986 time step was $56 \mathrm{~km}^{2}$ or $0.90 \%$ of the analysis area. 
Table 2. Classification Accuracy Statistics for all Image Dates.

\begin{tabular}{ccccc}
\hline Acquisition Date & Overall & $\begin{array}{c}\text { Water } \\
\text { (Producer's/User's) }\end{array}$ & $\begin{array}{c}\text { Undisturbed/ } \\
\text { Regenerated } \\
\text { (Producer's/User's) }\end{array}$ & $\begin{array}{c}\text { Disturbed } \\
\text { (Producer's/User's) }\end{array}$ \\
\hline $18 / 08 / 1986$ & $97.30 \%$ & $91.30 \% / 95.46 \%$ & $98.77 \% / 97.97 \%$ & $90.91 \% / 93.75 \%$ \\
$01 / 09 / 1991$ & $93.67 \%$ & $90.00 \% / 85.71 \%$ & $98.80 \% / 93.92 \%$ & $53.33 \% / 100.00 \%$ \\
$08 / 06 / 1995$ & $91.33 \%$ & $88.00 \% / 95.65 \%$ & $99.18 \% / 90.90 \%$ & $32.26 \% / 90.91 \%$ \\
$15 / 07 / 2000$ & $91.33 \%$ & $84.00 \% / 87.50 \%$ & $97.50 \% 92.13 \%$ & $54.29 \% / 86.36 \%$ \\
$22 / 08 / 2002$ & $89.33 \%$ & $80.00 \% / 90.91 \%$ & $98.22 \% / 88.76 \%$ & $54.00 \% / 93.11 \%$ \\
$08 / 05 / 2007$ & $84.33 \%$ & $78.57 \% / 95.65 \%$ & $98.03 \% / 82.23 \%$ & $46.38 \% / 91.43 \%$ \\
$02 / 09 / 2009$ & $85.00 \%$ & $77.78 \% / 87.50 \%$ & $97.71 \% / 84.86 \%$ & $38.18 \% / 84.00 \%$ \\
\hline
\end{tabular}

In the five year period from 1986-1991, the present disturbance class experienced $290 \mathrm{~km}^{2}(4.6 \%$ of the study area) of stand level disturbance. An area of $151 \mathrm{~km}^{2}$ of disturbance $(2.4 \%$ of the analysis area) occurred prior to 1986, which represented a significant decrease from the past disturbance class in the 1984-1986 period. The total surface area of disturbed forest in 1991 was $441 \mathrm{~km}^{2}$ or $7 \%$ of the study site. The average annual disturbance for the 1986-1991 time step was $58 \mathrm{~km}^{2}$ or $0.92 \%$ of the analysis area.

From 1991-1995, an area of $286 \mathrm{~km}^{2}$ (4.5\% of the study area) experienced stand level disturbance. It is characterized by a past disturbance area of $113 \mathrm{~km}^{2}$ that occurred prior to 1991 . The total surface area of disturbed forest in 1995 was $399 \mathrm{~km}^{2}$ or $6.3 \%$ of the study site. The average annual disturbance for the 1991-1995 time step was $72 \mathrm{~km}^{2}$ or $1.14 \%$ of the analysis area.

In the five year period from 1995-2000, an area of $374 \mathrm{~km}^{2}(5.9 \%$ of the study site) was subject to stand level disturbance. An area of $225 \mathrm{~km}^{2}$ (3.6\% of the study site) remained disturbed from prior periods. The total surface area of disturbed forest in 2000 was $599 \mathrm{~km}^{2}$ or $9.5 \%$ of the study site. The average annual disturbance for the 1995-2000 time step was $75 \mathrm{~km}^{2}$ or $1.19 \%$ of the analysis area.

An area of $122 \mathrm{~km}^{2}$ (1.9\% of the study site) experienced stand level disturbance from 2000-2002. The total surface area of disturbed forest in 2002 was $637 \mathrm{~km}^{2}$ or $10.1 \%$ of the study site. The average annual disturbance for the 2000-2002 time step was $61 \mathrm{~km}^{2}$ or $0.96 \%$ of the analysis area.

In the five year period from 2002-2007, an area of $302 \mathrm{~km}^{2}$ (4.8\% of the study site) was subject to stand level disturbance. In addition to the new occurrences during this period, an area of $526 \mathrm{~km}^{2}$ ( $8.4 \%$ of the study site) remains disturbed in from past activities. The total surface area of disturbed forest in 2007 was $828 \mathrm{~km}^{2}$ or $13.1 \%$ of the study site. The average annual disturbance for the 2002-2007 time step was $60 \mathrm{~km}^{2}$ or $0.96 \%$ of the analysis area.

Finally, in the two year period from 2007-2009, a total area of $75 \mathrm{~km}^{2}$ (1.2\% of the study site) experienced stand level disturbance. An area of $435 \mathrm{~km}^{2}$ (6.9\% of the analysis area) remains in the past disturbance class. The total surface area of disturbed forest in 2009 was $510 \mathrm{~km}^{2}$ or $8.1 \%$ of the study site. The average annual disturbance for the 2007-2009 time step was $37 \mathrm{~km}^{2}$ or $0.61 \%$ of the analysis area. 
Figure 4. 1984-1986 disturbance map.

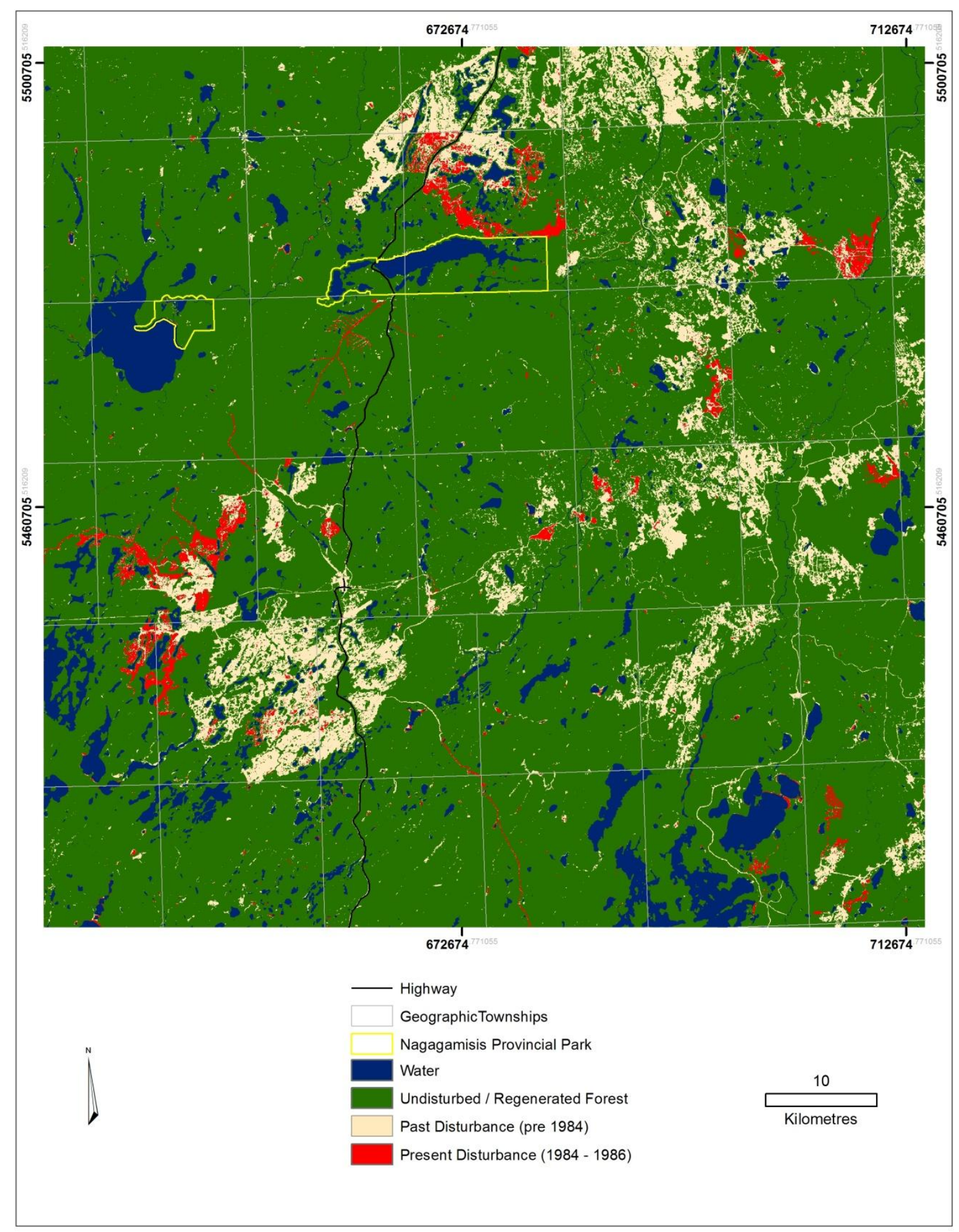

Over the course of the twenty-five year study period, from 1984 to 2009, stand level forest disturbance was experienced throughout the analysis area. Based on the results of the image differencing operations, a total area of $1649 \mathrm{~km}^{2}$ or $26.1 \%$ of the study site experienced stand level disturbance. The spatial distribution and size of the disturbance events that occurred during the study period are presented in the cumulative disturbance map (Figure 5). The divergent color ramp chosen to symbolize disturbance events ranges from a dark red that represents the most recent disturbance period 
(2007-2009) to a dark green that represents the oldest disturbance period (1984-1986). This color scheme does not imply the health condition or level of regeneration within disturbed areas, only the time period in which the disturbance event occurred. This map reveals a large amount of disturbance has occurred south of the Nagagamisis Central Plateau in Elgie, Newlands, Dowsley and Lessard Townships (refer to Figure 1) that spans almost the entire duration of the study period. There are also more recent disturbance events visible in the northwest corner of the study site in Frances, Downer and Mercer Townships. The overall patch size of disturbance events varies throughout the study site. There seems to be a pattern of larger patch sizes in the north and smaller patches in the southern portion of the study area.

Figure 5. Cumulative disturbance map 1984-2009.

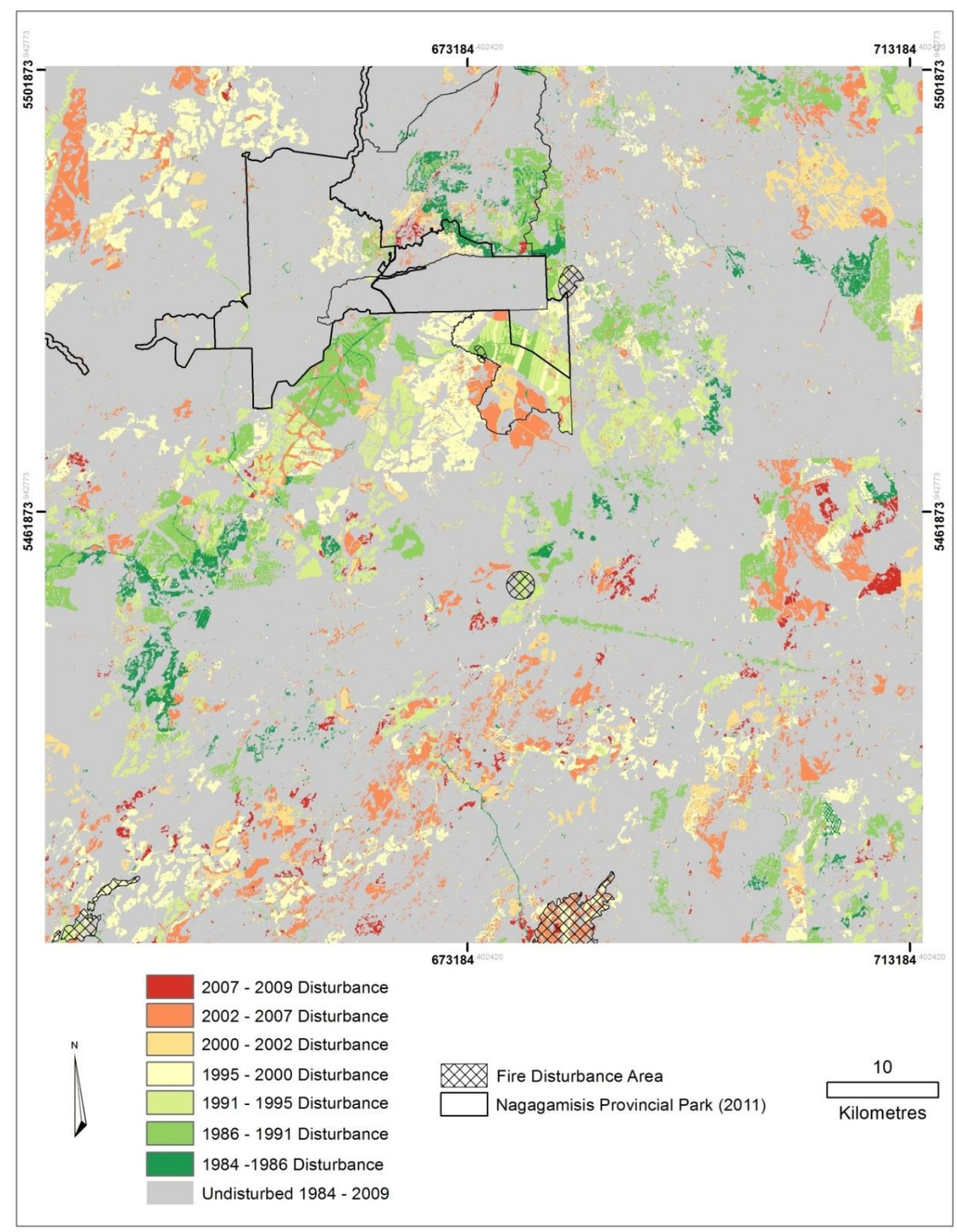


Trends of the stand level disturbance events were examined and visualized using time series graphs. Figure 6 represents the average annual disturbance area in square kilometres for each temporal period of the study. The 1984-1986 period had an annual average disturbance area of $56 \mathrm{~km}^{2}$ or $0.9 \%$ of the study area. From 1986 to 1991, the annual average disturbance area increased slightly to $58 \mathrm{~km}^{2}$ or $0.9 \%$ of the study site. In the 1991-1995 period, there was an increase to $72 \mathrm{~km}^{2}$ or $1.1 \%$ of the analysis area. Peak disturbance rates occurred during the 1995-2000 period with $75 \mathrm{~km}^{2}$ or $1.2 \%$ of the study area being affected. From 2000 to 2002, the average annual disturbance area decreased to $61 \mathrm{~km}^{2}$ or $1.0 \%$ of the study site. During the $2002-2007$ period, the average annual disturbance area was $60 \mathrm{~km}^{2}$ or $1.0 \%$ of the analysis area and from $2007-2009$ the total was $37 \mathrm{~km}^{2}$ or $0.6 \%$ of the study site.

Figure 6. Average annual disturbance (area in $\mathrm{km}^{2}$ ).

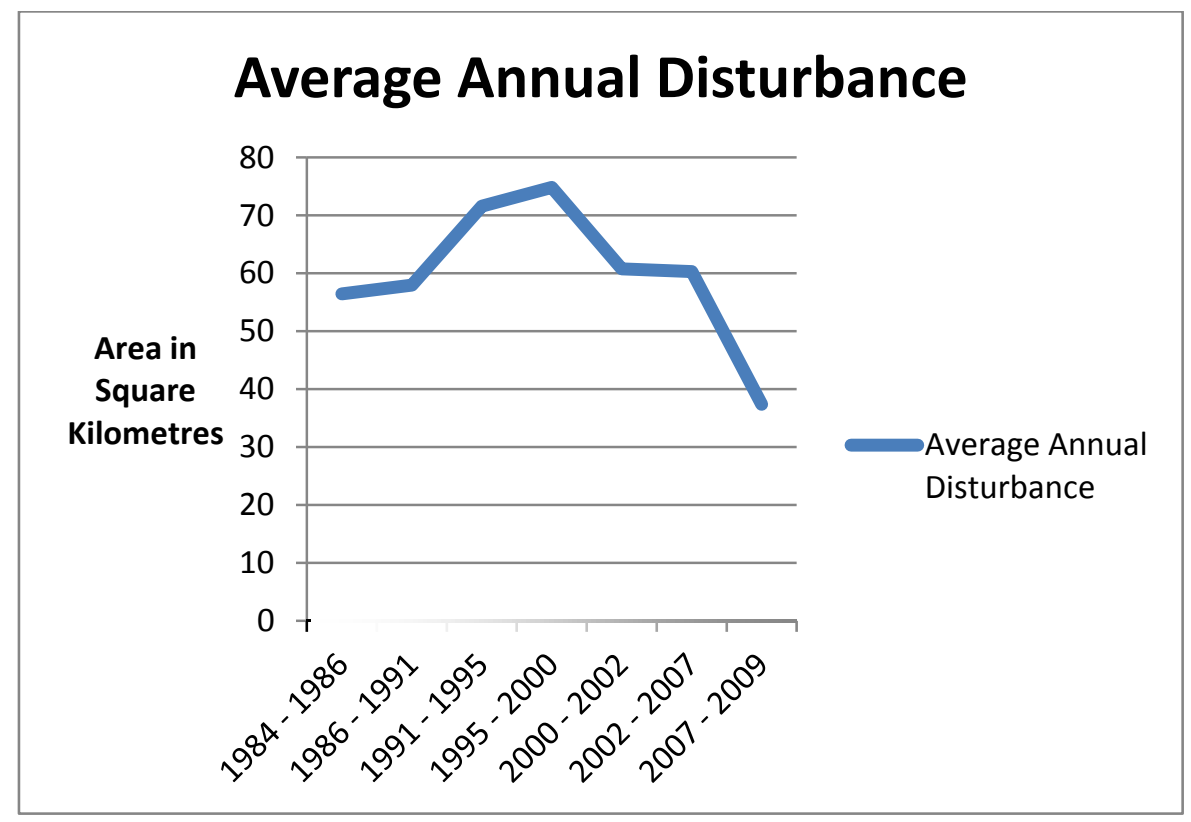

These data indicate a stable average annual disturbance of roughly $0.9 \%$ between 1984 and 1991 followed by an increase in average annual disturbance to just over $1.1 \%$ between 1991 and 1995 . Disturbance remains relatively stable at this level between 1995 and 2000 followed by a decrease in average annual disturbance between 2000 and 2002. Between 2002 and 2007 the average annual disturbance stabilizes at roughly $1.0 \%$, which is similar to the levels experienced between 1984 and 1991. The average annual disturbance fell significantly between 2007 and 2009 to a minimum of $0.6 \%$ at the end of the study period. The overall trend observed in these data indicates that the observed annual average disturbance values are stable at roughly $1.0 \%$ for the period of 1984 to 2007 and then begin to decline.

With regard to the Nagagamisis Central Plateau park lands, disturbance events have been abundant in the areas just outside of the provincial park boundaries. Large areas on all sides on the park lands experienced stand level disturbances during the 1984-2009 study period. Over the course of the study period, the Nagagamisis Provincial Park grew from $81 \mathrm{~km}^{2}$ in 1957 to more than $600 \mathrm{~km}^{2}$ today. The evolution and expansion of the park boundaries over time seems to occur after areas have experienced disturbances. In the case of the enhanced management zone, much of this area was disturbed by timber harvest in the 1970s and 1980s. This area has since been replanted and is developing into a thriving 
young forest [12]. The continued effort to preserve areas of natural and cultural heritage over the course of the study period demonstrates a strong commitment by the government and residents of Ontario. The expansion of Nagagamisis Central Plateau Signature Site will ensure the protection of these natural and cultural significant lands.

\section{Conclusions}

The combination of remote sensing techniques and data used to undertake this research has proven to be an effective method for mapping and monitoring forested lands after stand level disturbance events. The image classification methods made use of the original Landsat bands and vegetation indices: TCT and NDMI to produce results with overall classification accuracies ranging between 97.3\%-84.3\%. The band five difference images proved to be an accurate representation of changes to the vegetation and land cover after stand level forest disturbances within the study site.

The results of this research estimate the total area of forest disturbance over the study period of 1984-2009 to be $1649 \mathrm{~km}^{2}$ or $26.1 \%$ of the study site. The rates of disturbance were very consistent over the duration of the study period, around $1 \%$ of the analysis area per year. Large areas of disturbance seem to be concentrated in areas that are very close to Nagagamisis Provincial Park at each stage in its expansion. It is clear from the disturbance maps that protected areas are required to ensure preservation of significant cultural and historical locations. The land use planning strategy implemented through the Lands for Life and Ontario Living Legacy have contributed significantly to the protected area network. Within the study site, the total area of protected lands increased from $81 \mathrm{~km}^{2}$ in 1957 to more than $600 \mathrm{~km}^{2}$ today. This expansion has enhanced recreational activity and the preservation of natural and cultural heritage of the Nagagamisis Central Plateau Signature Site. Further investigation and planning will be required for guiding the land use of the enhanced management area for additional benefits.

By measuring stand level forest disturbance within the study site, and integrating change detection methods it was possible to monitor stand level forest disturbance over the course of a 25 year period from 1986-2009. Timber harvest activity has been identified as a prominent cause of disturbances within the study site. This research will contribute to understanding of the evolution of the Nagagamisis Central Plateau signature site within the surrounding forest management units. It establishes the rate and spatial distribution of stand level disturbance of forested lands within the study area.

The scope of this study was limited by several factors including atmospheric conditions. The dynamic atmospheric conditions of the study site and common mid-latitude cyclonic activity led to frequent cloud cover during the desired growing season acquisition window. This limitation led to the use of imagery that spanned the entire growing season and was not always close to anniversary dates between images. Ideally, imagery would have been collected on an annual basis, on the same day each year to minimize radiometric and phenological differences. In future work, the use of patch indices may be useful to determine if there have been any significant changes to timber harvest practices over the course of the study period. 


\section{Author Contributions}

The preparation and editing of this manuscript was performed by $\mathrm{K}$. Wayne Forsythe. Grant McCartney performed the initial image processing and classification work as part of his Master of Spatial Analysis degree program at Ryerson University under the supervision of K. Wayne Forsythe. The authors exchanged ideas and discussed the development of this paper throughout the writing process.

\section{Conflicts of Interest}

The authors declare no conflict of interest.

\section{References}

1. Brandt, J. The extent of the North American boreal zone. Environ. Rev. 2009, 17, 101-161.

2. Schroeder, T.A.; Wulder, M.A.; Healey, S.P.; Miosen, G.G. Mapping wildfire and clearcut harvest disturbances in boreal forest with Landsat time series data. Remote Sens. Environ. 2011, $115,1421-1433$.

3. Wulder, M.A.; White, J.C.; Gillis, M.D.; Walsworth, N.; Hansen, M.C.; Potapov, P. Multi-scale satellite and spatial information and analysis framework in support of a large-area forest monitoring and inventory update. Environ. Monit. Assess. 2010, 170, 417-433.

4. Kasischke, E.S.; Turetsky, M.R. Recent changes in the fire regime across the North American boreal region-Spatial and temporal patterns of burning across Canada and Alaska. Geophys. Res. Lett. 2006, 33, doi:10.1029/2006GL025677.

5. Weber, M.G.; Flannigan, M.D. Canadian boreal forest ecosystem structure and function in a changing climate: Impact on fire regimes. Environ. Rev. 1997, 5, 145-166.

6. Heinselman, M.L. Fire in the virgin forests of the Boundary Waters Canoe Area, Minnesota. Quat. Res. 1973, 3, 329-382.

7. Coops, N.C.; Wulder, M.A.; White, J.C. Understanding Forest Disturbance and Spatial Pattern: Remote Sensing and GIS Approaches; CRC Press (Taylor and Francis): Boca Raton, FL, USA, 2007.

8. Schroeder, D.; Perera, A.H. A comparison of large-scale vegetation patterns following clearcuts and fires in Ontario's boreal forests. For. Ecol. Manag. 2002, 159, 217-230.

9. Ontario Ministry of Natural Resources. Forest Management Units in Ontario; The Queens Printer for Ontario: Toronto, ON, Canada, 2011. Available online: http://www.mnr.gov.on.ca/en/ Business/Forests/2ColumnSubPage/STEL02_163522.html (accessed on 23 December 2013).

10. Perera, A.H.; Baldwin, D.J.B. Spatial Patterns in the Managed Forest Landscape of Ontario. In Ecology of a Managed Terrestrial Landscape. Patterns and Processes of Forest Landscapes in Ontario; Perera, A.H., Euler, D.L., Thompson, I.D., Eds.; UBC Press: Vancouver, BC, Canada, 2000; pp. 74-99.

11. Ontario Parks. It's in Our Nature: A Shared Vision for Parks and Protected Areas Legislation; The Queens Printer for Ontario: Toronto, ON, Canada, 2004. Available online: http://www.ontarioparks.com/english/discussion_paper.pdf (accessed on 23 December 2013). 
12. Ontario Ministry of Natural Resources. Nagagamisis Central Plateau: Background Information Summary; The Queens Printer for Ontario: Hearst, ON, Canada, 2002. Available online: http://www.ontarioparks.com/english/planning_pdf/naga_background.pdf (accessed on 23 December 2013).

13. Ontario Ministry of Natural Resources. Nagagamisis Central Plateau Signature Site Management Options; The Queens Printer for Ontario: Hearst, ON, Canada, 2004. Available online: http://www.ontarioparks.com/english/planning_pdf/naga_manage_opt.pdf (accessed on 23 December 2013).

14. Cohen, W.B.; Goward, S.N. Landsat's role in ecological applications of remote sensing. BioScience 2004, 54, 535-545.

15. Lunetta, R.S.; Johnson, D.M.; Lyon, J.G.; Crotwell, J. Impacts of imagery temporal frequency on land-cover change detection monitoring. Remote Sens. Environ. 2004, 89, 444-454.

16. Masek, J.G.; Lindsay, F.E.; Goward, S.N. Dynamics of urban growth in Washington DC metropolitan area 1973-1996 from Landsat observations. Int. J. Remote Sens. 2000, 21, 3473-3486.

17. Forsythe, K.W.; Waters, N.M. The utilization of image texture measures in urban change detection. Photogramm.-Fernerkund.-Geoinforma. 2006, 4, 287-296.

18. Masek, J.G.; Huang, C.; Wolfe, R.; Cohen, W.; Hall, F.; Kutler, J.; Nelson, P. North American forest disturbance mapped from a decadal Landsat record. Remote Sens. Environ. 2008, 112, 2914-2926.

19. Coppin, P.R.; Bauer, M.E. Digital change detection in forest ecosystems with remotely sensed imagery. Remote Sens. Rev. 1996, 13, 207-234.

20. Sader, S.A.; Bertrand, M.; Wilson, E.H. Satellite change detection of forest harvest patterns on an industrial forest landscape. For. Sci. 2003, 49, 341-353.

21. Potapov, P.; Turubanova, S.; Hansen, C. Regional-scale boreal forest cover and change mapping using Landsat data composites for European Russia. Remote Sens. Environ. 2011, 115, 548-561.

22. Xin, Q.; Olofsson, P.; Zhu, Z.; Tan, B.; Woodcock, C.E. Toward near real-time monitoring of forest disturbance by fusion of MODIS and Landsat data. Remote Sens. Environ. 2013, 135, 234-247.

23. Gluck, M.J.; Rempel, R.S. Structural characteristics of post-wildfire and clearcut landscapes. Environ. Mon. Assess. 1996, 39, 435-440.

24. Cohen, W.B.; Spies, T.A.; Alig, R.J.; Oetter, D.R.; Maiersperger, T.K.; Fiorella, M. Characterizing 23 years (1972-1995) of stand replacement disturbances in western Oregon forests with Landsat imagery. Ecosystems 2002, 5, 122-137.

25. Kennedy, R.E.; Yang, Z.; Cohen, W.B. Detecting trends in forest disturbance and recovery using yearly Landsat time series: 1. LandTrendr-Temporal segmentation algorithms. Remote Sens. Environ. 2010, 114, 2897-2910.

26. Cohen, W.B.; Harmon, M.; Wallin, D.; Fiorella, M. Two decades of carbon flux from forests of the Pacific Northwest. BioScience 1996, 46, 836-844.

27. Cohen, W.B.; Fiorella, M.; Gray, J.; Helmer, E.; Anderson, K. An efficient and accurate method for mapping forest clearcuts in the Pacific Northwest using Landsat imagery. Photogramm. Eng. Remote Sens. 1998, 64, 293-300. 
28. Hall, F.G.; Botkin, D.B.; Strebel, D.E.; Woods, K.D.; Goetz, S.J. Large-scale patterns of forest succession as determined by remote sensing. Ecology 1991, 72, 628-640.

29. Frate, L.; Carranza, M.L. Quantifying landscape-scale patterns of temperate forests over time by means of neutral simulation models. ISPRS Int. J. Geo-Inf. 2013, 2, 94-109.

30. Abrate, M.; Bacciu, C.; Hast, A.; Marchetti, A.; Minutoli, S.; Tesconi, M. GeoMemories-A platform for visualizing historical, environmental and geospatial changes in the Italian landscape. ISPRS Int. J. Geo-Inf. 2013, 2, 432-455.

31. Yeshaneh, E.; Wagner, W.; Exner-Kittridge, M.; Legesse, D.; Blöschl, G. Identifying land use/cover dynamics in the Koga Catchment, Ethiopia, from multi-scale data, and implications for environmental change. ISPRS Int. J. Geo-Inf. 2013, 2, 302-323.

32. Moskal, L.M.; Jakubauskas, M.E. Monitoring post disturbance forest regeneration with hierarchical object-based image analysis. Forests 2013, 4, 808-829.

33. Ricotta, C.; Carranza, M.L. Measuring scale-dependent landscape structure with Rao's quadratic diversity. ISPRS Int. J. Geo-Inf. 2013, 2, 405-412.

34. Coppin, P.R.; Bauer, M.E. Processing of multitemporal Landsat TM imagery to optimize extraction of forest cover change features. IEEE Geosci. Remote Sens. 1994, 60, 287-298.

35. Wilson, E.H.; Sader, S.A. Detection of forest harvest using multiple dates of Landsat TM imagery. Remote Sens. Environ. 2002, 80, 385-396.

36. Jin, S.; Sader, S.A. Comparison of time series tasselled cap wetness and the normalized difference moisture index in detecting forest disturbance. Remote Sens. Environ. 2005, 94, 364-372.

37. Rowe, J.S. Forest Regions of Canada; Publication No. 13000, Department of the Environment, Canadian Forest Service: Ottawa, ON, Canada, 1972.

38. Ekstrom, B. Forest Management Plan for the Hearst Forest, Hearst District, Northeast Region, Hearst Forest Management including Hearst, Ontario, 2007. Available online: http://www.hearstforest.com/ english/PDF/HearstForest2007FMP.pdf (accessed on 23 December 2013).

39. Ontario Parks. Nagagamisis Provincial Park; The Queens Printer for Ontario: Toronto, ON, Canada, 2010. Available online: http://www.ontarioparks.com/park/nagagamisis (accessed on 23 December 2013).

40. Crist, E.P.; Cicone, R.C. A physically based transformation of Thematic Mapper data-The TM tasseled cap. IEEE Trans. Geosci. Remote Sens. 1984, 22, 256-263.

41. Kauth, R.J.; Thomas, G.S. The Tasselled Cap-A Graphic Description of Spectral-Temporal Development of Agricultural Crops as Seen by Landsat. In Proceedings of the 2nd International Symposium on Machine Processing of Remotely Sensed Data, Purdue University, West Lafayette, IN, USA, 29 June-1 July 1976.

42. Franklin, S.E.; Lavigne, M.B.; Moskal, L.M.; Wulder, M.B.; McCaffrey, T.M. Interpretation of forest harvest conditions in New Brunswick using Landsat TM ENHANCED Wetness Difference Imagery (EWDI). Can. J. Remote Sens. 2001, 27, 118-128.

43. Healey, S.P.; Cohen, W.B.; Yang, Z.; Krankina, O.N. Comparison of Tasseled Cap-based Landsat structures for use in forest disturbance detection. Remote Sens. Environ. 2005, 97, 301-310.

44. Horler, D.N.H.; Ahern, F.J. Forestry information content of Thematic Mapper data. Int. J. Remote Sens. 1986, 7, 405-428. 
45. Cohen, W.B.; Spies, T.A.; Fiorella, M. Estimating the age and structure of forests in a multi-ownership landscape of western Oregon, USA. Int. J. Remote Sens. 1995, 16, 721-746.

46. Goodwin, N.R.; Coops, N.C.; Wulder, M.A.; Gillanders, S.; Schroeder, T.A.; Nelson, T. Estimation of insect dynamics using a temporal sequence of Landsat data. Remote Sens. Environ. 2008, 112, 3680-3689.

47. Sader, S.A.; Winne, J.C. RGB-NDVI colour composites for visualizing forest change dynamics. Int. J. Remote Sens. 1992, 13, 3055-3067.

48. Ranson, K.J.; Kovacs, K.; Sun, G.; Kharuk, V.I. Disturbance recognition in the boreal forest using radar and Landsat-7. Can. J. Remote Sens. 2003, 29, 271-285.

49. Natural Resources Canada. The Nature of Forest Fires. In The State of Canada's Forests 2003-2004; Canadian Forest Service, Headquarters, Policy, Planning and International Affairs Branch: Ottawa, ON, Canada, 2004; pp. 45-55.

50. Lillesand, T.M.; Kiefer, R.W.; Chipman, J.W. Remote Sensing and Image Interpretation, 6th ed.; John Wiley and Sons Inc.: Hoboken, NJ, USA, 2008; pp. 585-604.

51. Hame, T.I.; Heller, J.S.; Miguel-Ay, A. An unsupervised change detection and recognition system for forestry. Int. J. Remote Sens. 1998, 19, 1079-1099.

52. Congalton, R.G.; Green, K. Assessing the Accuracy of Remotely Sensed Data: Principles and Practices; Lewis Publishers: Boca Raton, FL, USA, 1999.

53. Senseman, G.M.; Bagley, C.F.; Tweddale, S.A. Accuracy Assessment of the Discrete Classification of Remotely-Sensed Digital Data for Landcover Mapping; Technical Report EN-95/04; USACERL: Champaign, IL, USA, 1995.

54. Grenier, M.; Labrecque, S.; Benoit, M.; Allard, M. Accuracy Assessment Method for Wetland Object-Based Classification. In Proceedings of the GEOBIA 2008-Pixels, Objects, Intelligence, GEOgraphic Object Based Image Analysis for the 21st Century, Calgary, AB, Canada, 5-8 August 2008; Hay, G.J., Blascke, T., Marceau, D., Eds.; International Society for Photogrammetry and Remote Sensing: Hannover, Germany, 2008.

55. Forsythe, K.W.; Schatz, B.; Swales, S.J.; Ferrato, L.-J.; Atkinson, D.M. Visualization of lake mead surface area changes from 1972 to 2009. ISPRS Int. J. Geo-Inf. 2012, 1, 108-119.

56. Coppin, P.R.; Jonckheere, I.; Nackaerts, K.; Muys, B. Digital change detection methods in ecosystem monitoring: A review. Int. J. Remote Sens. 2004, 25, 1565-1596.

(C) 2014 by the authors; licensee MDPI, Basel, Switzerland. This article is an open access article distributed under the terms and conditions of the Creative Commons Attribution license (http://creativecommons.org/licenses/by/3.0/). 